\title{
Karyotype features of trematode Himasthla elongata
}

Anna I. Solovyeva ${ }^{1 *}$, Vera N. Stefanova', Olga I. Podgornaya ${ }^{1,2,3}$ and Serghei lu. Demin ${ }^{1}$

\begin{abstract}
Background: Trematodes have a complex life cycle with animal host changes and alternation of parthenogenetic and hermaphrodite generations. The parthenogenetic generation of the worm (rediae) from the first intermediate host Littorina littorea was used for chromosome spreads production. Karyotype description of parasitic flatworm Himasthla elongata Mehlis, 1831 (Digenea: Himasthlidae) based on fluorochrome banding and 18S rDNA mapping.

Results: Chromosome spreads were obtained from cercariae embryos and redial tissue suspensions with high pressure squash method.74.4\% of the analysed spreads contained 12 chromosome pairs $(2 n=24)$. Chromosome classification was performed according to the morphometry and nomenclature published. H. elongata spread chromosomes had a rather bead-like structure. Ideograms of DAPI-banded chromosomes contained 130 individual bands. According to flow cytometry data, the H. elongata genome contains 1.25 pg of DNA, so one band contains, on average, 9.4 Mb of DNA. Image bank captures of individual high-resolution DAPI-banded chromosomes were provided. Differential DAPI- and $\mathrm{CMA}_{3}$-staining revealed the chromatin areas that differed in AT- or GC-content. Both dyes stained chromosomes all along but with varying intensities in different areas. FISH revealed that vast majority (95.0 \%) of interphase nuclei contained one signal for $18 \mathrm{~S}$ rDNA. This corresponded to the number of nucleoli per cell detected by observations in vivo. The rDNA signal was observed on one or two homologs of chromosome 10 in $72.2 \%$ of analysed chromosome spreads, therefore chromosome 10 possessed the main rDNA cluster and minor ones on chromosomes 3 and 6, that corresponds with AgNOR results.

Conclusions: Himasthla elongata chromosomes variations presented as image bank. Differential chromosome staining with fluorochromes and FISH used for $18 \mathrm{~S}$ rDNA mapping let us to conclude: (1) Himasthla elongata karyotype is $2 n=24$; (2) chromosome number deviates from the previously studied echinostomatids $(2 n=14-22)$; (3). Chromosome 10 possesses the main rDNA cluster with the minor ones existing on chromosomes 3 and 6.
\end{abstract}

Keywords: Himasthla elongata, Digenea, Karyotype, 18S rDNA mapping

\section{Background}

The digenetic trematodes, or flukes, are ones of the most common and abundant of parasitic worms. They act as parasites on all classes of vertebrates, especially marine fishes, and nearly every organ of the vertebrate body can be parasitised by some kind of trematode, adult or juvenile [1]. Many trematode species are the causative agents for massive zoonosises. The list of flukes infectious to humans is quite large, and because of their importance, numerous investigations have been initiated, especially regarding parasite-host interactions [1]. $\mathrm{Hu}-$ man parasites as model objects require appropriate

* Correspondence: orcinuca@gmail.com

${ }^{1}$ Institute of Cytology RAS, St. Petersburg 194064, Russia

Full list of author information is available at the end of the article laboratory conditions. The subclass Digenea comprises about 18000 species and it is possible to find a safe alternative for parasite research. Genus Himasthla is an example of a safe research option. There are 25 presently described species of Himasthla Mehlis, 1831 (Digenea: Himasthlidae [2]). Just two of them were found in fishes and one in humans; all three cases seemed to be accidental infections [3]. However, most are studied quite insufficiently, excepting Himasthla elongata (Mehlis, 1831), which became a new model for ecological, immunologic and molecular investigations [4-7].

$H$. elongata is common in the coastal ecosystems of northern European seas. Like other trematodes, it has a complex lifecycle dependent on of host and parthenogenetic (redia, cercaria) and hermaphrodite generations. 
The first intermediate hosts of this parasite are intertidal snails of the Littorina (Gastropoda, Prosobranchia) genus and the second intermediate hosts are the intertidal bivalves, Mytilus edulis and Cerastoderma edule; gulls are its final hosts [8].

Trematode metacercariae parasitising bivalve molluscs may influence the vital functions of the hosts, lowering their resistance to unfavourable environmental factors and, in the case of intensive infection, even causing their death and resulting in mass mollusc mortality [4].

Cytogenetic studies of parasites are useful not only for understanding systematics, but also the basic mechanisms underlying parasitic agents. Among invertebrates, chromosome mapping has been carried out for a few model organisms due to methodological difficulties.

$H$. elongata becomes a model for zoological and molecular studies, but it has not been studied at the cytogenetic level. The lack of knowledge about karyotype makes problems for genomic investigation. Moreover, propelled by ever-increasing throughput and decreasing costs, next generation sequencing (NGS) has produced a growing number of genomes and transcriptomes sequenced (existing in databases) and it looks like the $H$. elongata genome will be sequenced soon. Newly sequenced genome should be assembled and attached to a chromosome's physical map, thus it is necessary to acquire the data on its karyotype. The purpose of the current study is the description of $H$. elongata chromosomes. DNA sequence mapping is most convenient for carrying out counterstaining chromosome bands with fluorochromes. DAPI excitation emission varies in proportion to the AT-content of DNA and chromatin condensation level [9]. We elaborated protocols for chromosome preparation and fluorescence in situ hybridisation (FISH), enabling conservation of the typical pattern of DAPI-banding for all components of the karyotype. To establish the position of GC-rich bands on individual chromosome sets, a GC-specific fluorochrome, chromomycin $\mathrm{A}_{3}\left(\mathrm{CMA}_{3}\right)$, was used for staining in addition to DAPI counterstaining. The present study is focused on karyotype description of the parasitic flatworm, $H$. elongata, based on fluorochrome banding and $18 \mathrm{~S}$ rDNA mapping.

\section{Methods}

\section{Sampling site and collection of parasites}

A collection of periwinkles infected with $H$. elongata was obtained from, along with cell suspension preparation carried out at the White Sea Biological Station of the Zoological Institute of the Russian Academy of Sciences situated in the Chupa Inlet, the Kandalaksha Bay of the White Sea $\left(66^{\circ} 20^{\prime} \mathrm{N}\right.$; $\left.33^{\circ} 38^{\prime} \mathrm{E}\right)$ during July and early August in 2012 and 2013. Digeneans were identified on the basis of their mollusc hosts and their morphological [3] and molecular (18S rDNA) features. At least 8 snails with only $H$. elongata infection i.e. 8 populations of $H$. elongata parthenogenetic larvae obtained from their hosts were used in cytogenetic experiments.

\section{Intravital observations}

Live materials were observed under a Leika DM2500 microscope. Dark field illumination at low magnification (objective 10x) was realised by use of the $\mathrm{Ph} 3$ phase diaphragm in combination with closed differential interference contrast (DIC) prisms. DIC was utilized for observations under the $100 \times$ DIC objective.

\section{Metaphase chromosome spread preparation}

$H$. elongata parthenitae - rediae were obtained in amount of several hundreds individuals from each L. littorea snails and washed from the host tissue by three exchanges of seawater filtered through a $0.22 \mathrm{~mm}$ Millipore filter. The worms were incubated in Leiboviz L-15 (Sigma) medium with $0,01 \mathrm{mg} / \mathrm{ml}$ gentamycin (PanECO, Russia) and $0.1 \%$ colchicine (PanECO, Russia) for $4 \mathrm{~h}$ at room temperature and treated with hypotonic solution $(5 \mathrm{mM} \mathrm{KCl})$ for $40 \mathrm{~min}$, then fixed with Carnoy's solution (methanol:glacial acetic acid mixture; 3:1). Fixed rediae were repeatedly passed through the syringe with a $22 \mathrm{G}$ needle. The suspension was placed in $15 \mathrm{ml}$ tubes and kept still for 3-5 min to sediment large fragments. The top phase was collected and centrifuged three times at $2.5 \mathrm{krpm}$ for $10 \mathrm{~min}$ with the three changes of fixative and stored at $-20{ }^{\circ} \mathrm{C}$ until slide preparation. Chromosome spreads were prepared according to classic cytogenetical protocols used for trematodes [10-15] with convenient air-drying method, along with more recent techniques, such as highpressure squash preparation $[16,17]$. The convenient air-drying method was performed as follows: 4 or 5 drops of cell suspension were carefully placed onto slides which had been previously chilled in ice water for maintaining a thin film of water at the time when the drops fall on the slide from a height of about $20 \mathrm{~cm}$. Slides were air-dried and then stored at $-20{ }^{\circ} \mathrm{C}$ until staining. A modified protocol from Deng et al. [14] was performed the next way: the washed slides were placed an a stainless steel bar inside a moist chamber. $30 \mu \mathrm{l}$ of cell suspension were dropped on each slide Then the moist chamber was at $50{ }^{\circ} \mathrm{C}$ in thermostat until fixative drying.

\section{High-pressure squash preparation}

Whole $H$. elongata rediae were fixed after colchicine and hypotonic solution treatment and used for spreading chromosomes. On average 50 rediae from different snails were used for slides preparations. The suspension 
of dissociated into small pieces worms' tissues was dropped on slides containing Carnoy's solution on the surface. The spread cells were coated with a $50.0 \%$ propionic acid drop and then covered by $24 \times 24 \mathrm{~mm}$ cover slips immediately after fixative evaporation. A mechanical vise was used to evenly apply pressure to further flatten chromosomes on the preparation. Approximately $150 \mathrm{~kg} / \mathrm{cm}^{2}$ of pressure through the precision vise was gradually applied during 90-120 second intervals. At that point, the slides were placed into liquid nitrogen and the cover slips were removed. Afterwards, the slides were dehydrated in a series of ethanol $(70.0,80.0$, and $100.0 \%$ ), air-dried and kept in $-20{ }^{\circ} \mathrm{C}$ until staining.

\section{Giemsa staining}

The slides were stained in a $3.0 \%$ solution of Giemsa dye (Merck, USA) in phosphate buffer solution ( $\mathrm{pH}$ 6.8) for $12 \mathrm{~min}$ and flushed with flowing water.

\section{Fluorescent in situ hybridization with 18S rDNA probe}

As the $H$. elongata genome is not yet sequenced and $18 \mathrm{~S}$ rDNA is quite conservative, a small subunit ribosomal probe was generated by polimerase chain reaction (PCR) using the 18Sa forward primer (AACCTGGTTGAT CCTGCCA) and the $18 \mathrm{Sb}$ reverse primer (GATCCTT CTGCAGGTTCACCTAC) [18]. The PCR product was sequenced in order to confirm its attribution to $18 \mathrm{~S}$ rDNA and submitted to GenBank (KU886143). The analysis of a $18 \mathrm{~S}$ rDNA probe sequence was performed with the BLAST tool [19]. Isolation of genomic DNA was performed according to Winnenpeninx [20]. The probes were labelled with biotin-14-dUTP under appropriate conditions. Slide pretreatment was performed according to Khodyuchenko et al. [21] with modifications: chromosome preparations were digested with $100 \mu \mathrm{g} / \mathrm{ml}$ RNase $\mathrm{A}$ in $2 \times \mathrm{SSC}$ for $1 \mathrm{~h}$ at $37{ }^{\circ} \mathrm{C}$ and washed twice in $2 \times \mathrm{SSC}$ for $5 \mathrm{~min}$ each, then prefixed with $2.0 \%$ PFA for $15 \mathrm{~min}$, and then washed with $1 \times \mathrm{PBS}$ three times for $5 \mathrm{~min}$ at a time and incubated in $0.1 \%$ Triton X-100 for $10 \mathrm{~min}$ and washed again with $1 \times$ PBS. Hybridisation at $37{ }^{\circ} \mathrm{C}$ for $18 \mathrm{~h}$ was followed by the washes, which included $0.2 \times \operatorname{SSC}\left(3 \times 5 \mathrm{~min}, 60^{\circ} \mathrm{C}\right)$ and $2 \times \operatorname{SSC}\left(3 \times 5 \mathrm{~min}, 42{ }^{\circ} \mathrm{C}\right)$. Probe signals were detected with streptavidin - Alexa Fluor 594 conjugate (Life technologies, USA) in blocking solution. The slides were counterstained with Slow Fade Gold Antifade with DAPI (Molecular Probes, USA).

\section{Double Chromomycin $A_{3}$ - DAPI staining}

The slides were stained with Chromomycin $\mathrm{A}_{3}\left(\mathrm{CMA}_{3}\right)$ based on Schweizer [22] with several modifications. The stock solution of chromomycin $\mathrm{A}_{3}$ (Sigma-Aldrich) $(1 \mathrm{mg} / \mathrm{ml})$ was prepared by dissolution in deionised water without stirring for several days at $4{ }^{\circ} \mathrm{C}$ in the dark.
Older solutions tend to stain better. Working solution of $\mathrm{CMA}_{3}(0.5 \mathrm{mg} / \mathrm{ml})$ was prepared by dissolving (1:1) the stock solution in Mcllvaine's buffer $(\mathrm{pH}=7.0)$ with $5 \mathrm{mM}$ $\mathrm{MgCl}_{2}$. Slides were rinsed in Mcllvaine's buffer and placed in $\mathrm{CMA}_{3}$ working solution under a coverslip and stained in the dark at RT for 1 to 2 hours. To remove the coverslip, the slides were briefly washed in Mcllvaine's buffer and air-dried. After that a few drops of DAPI solution are placed on slides and covered with a coverslips. Slides are stained in the dark for $20-30 \mathrm{~min}$ at RT, rinsed in Mcllvaine's buffer and air-dried. DAPI stock solution $(1 \mathrm{mg} / \mathrm{ml})$ is prepared on deionized water and can be stored frozen in dark for a year. DAPI working solution $(0.8 \mathrm{mkg} / \mathrm{ml})$ is prepared on Mcllvaine's buffer $(\mathrm{pH}=7.0)$ usually fresh before use. Then the slides were mounted in ProLongR Gold antifade (Invitrogen) and sealed with nail polish. Stained slides were aged for 3 to 5 days in the dark at $4{ }^{\circ} \mathrm{C}$ to stabilise $\mathrm{CMA}_{3}$ fluorescence before examination.

\section{Fluorescence microscopy}

Chromosome spreads were examined with a Leica Fluorescence Microscope DMI 6000B (Leica Wetzlar $\mathrm{GmbH}$, Germany) at the Development of Molecular and Cellular Technologies Resource Centre at SaintPetersburg State University. Images were taken with a $100 \times / 1.4$ oil immersion objective using appropriate filter cubes fluorescent dyes, like $\mathrm{CMA}_{3}(430-480 \mathrm{~nm})$, Alexa 594 and DAPI(360-390 nm), and recorded using a monochrome-cooled CCD camera. Karyological data of $H$. elongata (relative length and centromeric index) were calculated in 64 best spreads out of 100 evaluated spreads with Image Tool 3.0 software [23]. The centromere position on the chromosomes was classified according to the nomenclature of Levan et al. [24]. Negative images of DAPI-stained chromosomes were enhanced in Adobe Photoshop version 4 as described before [25].

\section{Results}

Identification of a prometaphase and metaphase chromosome source among larval cells was carried out by comparing cell morphology at preparations of shredded and fixed rediae tissues with preparations of live juvenile cercariae or embryos at different developmental stages. Cytological preparations stained with Giemsa contained cells of various sizes and morphology (Fig. 1a, b). All slides contained large amounts of resting cells, which contained a round or oval 6-8 $\mu \mathrm{m}$ diameter nuclei, uniformly filled with condensed chromatin, and possessed a narrow cytoplasm rim with a width of $1 \mu \mathrm{m}$. The vast majority of chromosome spreads were determined among the large round or oval cells with a $10-20 \mu \mathrm{m}$ core diameter, representing no more than $1.0-5.0 \%$ of all cells in 


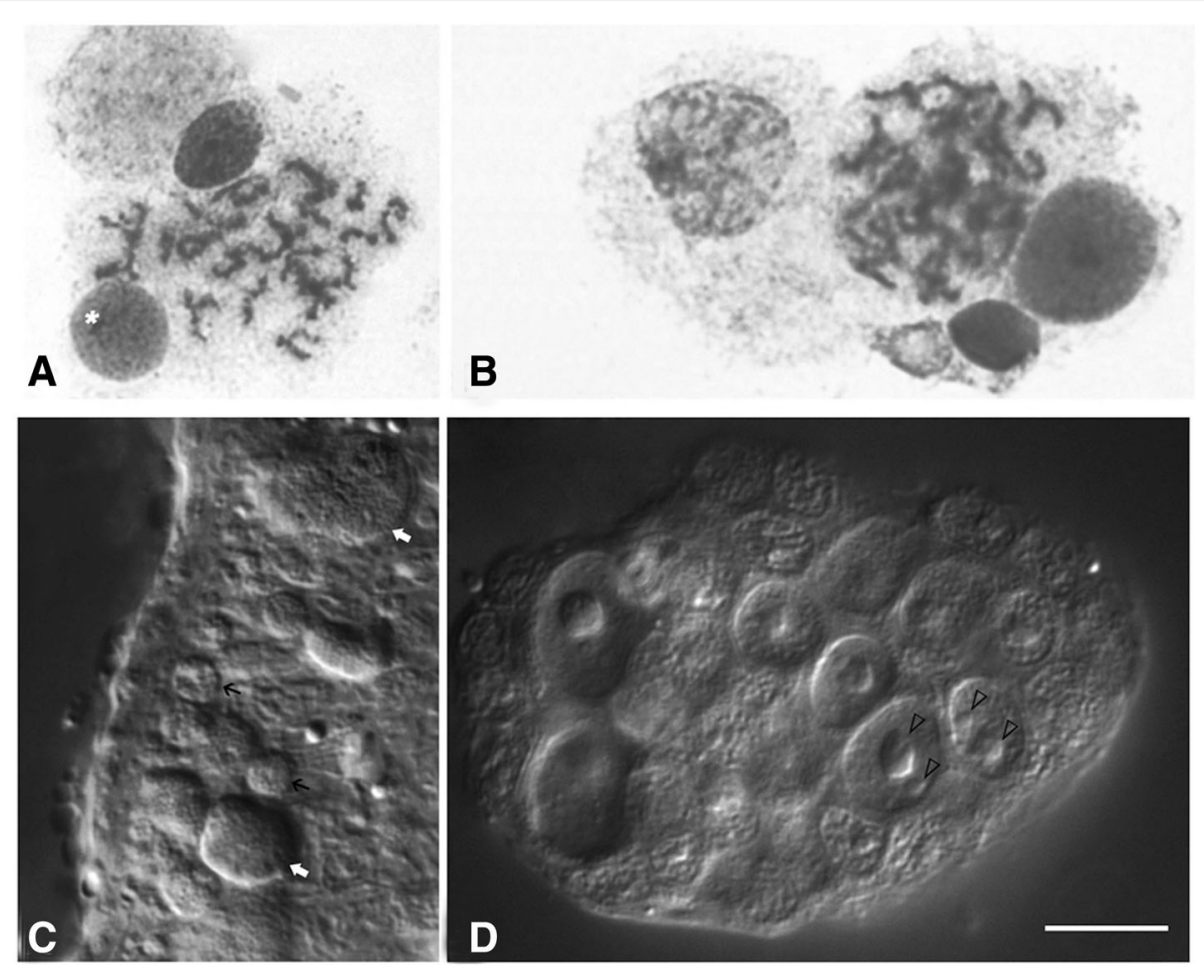

Fig. 1 a, b flattened small pieces of tissues with large sized prometaphase-metaphase and interphase cells in association with small sized, probably senescent or stem cells (asterisk), dissociated mature rediae (Giemsa staining). c, d DIC images of alive juvenile cercaria (lateral fragment of the body) and its embryo; (c) - tegumental margin with large subtegumental glandular cells (white arrows) and small, probably senescent or stem cells (black arrows); (d) cercarial embryo, nucleoli are visible (arrowheads). Scale bar - $10 \mu \mathrm{m}$

the preparation. These cells had either an acentric core and a developed cytoplasm or a centrally located nucleus and a narrow (no wider than $3 \mu \mathrm{m}$ ) layer of cytoplasm (Fig. 1c, d). According to histological and cytological features, the large cells located near the tegument may correspond to subtegumental glandular cells - socalled cyton precursors, - the tegument nucleus-bearing compound [26]. This source was used for chromosome preparations. The prometaphase spreads were obtained with a high pressure $\left(\sim 150 \mathrm{~kg} / \mathrm{cm}^{2}\right)$ spreading technique [16] applied to the cell suspension, made from shredded rediae and cercariae embryos. Compared with a convenient air-drying method and a complexed protocol described by Deng et al. [14], the chromosomes, treated with pressure had a much better bands resolution, therefore we considered to call them "high-resolution" chromosomes. An example of a metaphase chromosomes' DAPI-banding pattern is shown in Fig. 2.

About $74.4 \%$ of the spreads analysed contained 12 chromosome pairs $(2 n=24)$, while the others were aneuploid. Generally, $H$. elongata chromosomes had a rather bead-like structure than a banded one. Prometaphasemetaphase chromosomes of $H$. elongata large sized cells relatively rare had conjugated sister chromatids (SCs). Usually their SCs were dissociated elsewhere for the exception of centromeric region. X- or $\Lambda$-shaped chromosome figures that is considered typical only for metaphase, formed as the result. Sister chromatids were associated only in the centromere region in approximately half of the typical prometaphase-metaphase chromosomes with dissociated SCs. In the other half, they had a conjugated SCs yielding to a rod-shaped or I-shaped form. Chromomeric patterns of sister chromatids for the chromosomes with dissociated SCs were similar but not the same. Such chromosomes consisted of two $0.5-2 \mu \mathrm{m}$ collaterally-associated chromatin strands with clearly visible primary (centromeric) constriction. Such primary constriction was observed quite rarely in chromosomes with conjugated SCs. The frequencies chromosomes with different type of SCs association observed in prometaphase-metaphase spreads are summarised in Table 1.

The difference in chromosome shapes may reflect the dynamics of sister chromatid segregation during cell division (Table 1). Not a single spread exhibited complete segregation, i.e. in all the set (24) with 2 chromatids, usually about half of the set already went through segregation. Metaphase DAPI-banded karyotype of $\mathrm{H}$. elongata $(2 \mathrm{n}=24$, Fig. 2$)$ allows chromosomes' classification. Table 2 demonstrates the morphometric data for each 


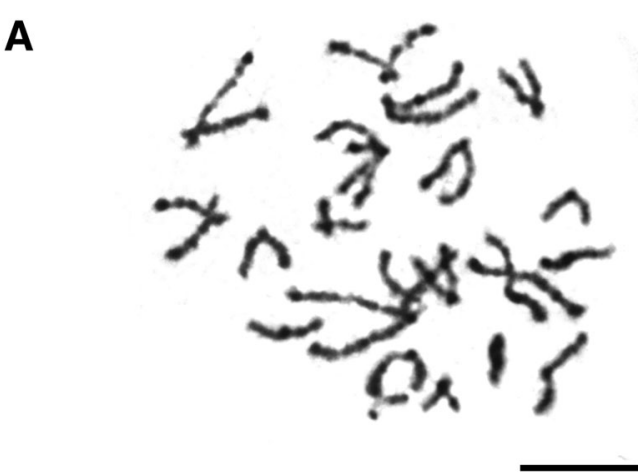

B

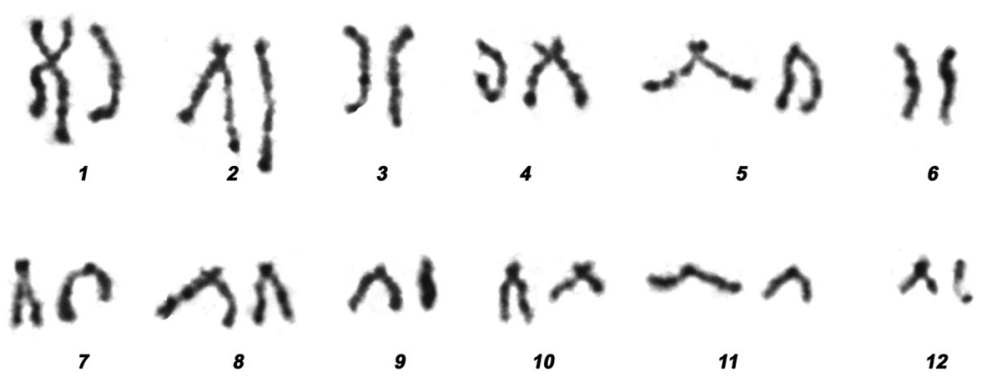

Fig. $\mathbf{2}$ a H.elongata DAPI-stained chromosome spreads in grey scale. b karyotype shown in a. Scale bar - $10 \mu \mathrm{m}$

set of chromosomes. All measurements and centromeric index calculations were performed for metaphase chromosomes with dissociated SCs. Pairs 2, 4-7 and 11 and 12 can accurately be classified as subtelocentric, pair 3 - metacentric. The classification of chromosomes 1 $(\mathrm{m}-\mathrm{sm})$ and 8-10 (sm-st) is uncertain for centromeric index values $\mathrm{SD}$ is on the border of two types [24].

High-resolution DAPI-banded $H$. elongata chromosome ideogram construction was based on the results of relative chromosome length and the centromeric index counted (Table 2) as well as morphology. Graphic ideograms were based on the negative image of DAPIbanded chromosomes with maximum bands resolution. $H$. elongata chromosomes possess a typical chromomere (necklace-like) structure. Such morphology is characteristic of human and animal pachytene meiotic chromosomes, but not mitotic chromosomes [27, 28]. All chromosomes contained a block of centromeric heterochromatin. Homologous chromosomes within a single cell could possess centromeric heterochromatin of different sizes; they also vary at different metaphase plates. Ideograms of $H$. elongata high-resolution DAPI-banded chromosomes contain 130 individual bands resolved in haploid chromosomes set (Fig. 3). According to flow cytometry data, the $H$. elongata genome contains $1.25 \mathrm{pg}$ of DNA [29] (for a detailed information see Additional file 1: Figure S1 and Additional file 2: Supplementary methods). Simple recalculation $(1 \mathrm{pg}$ DNA $=978 \mathrm{Mb}$ ) [30] shows that one band in $H$. elongata chromosome contains, on average $9.4 \mathrm{Mb}$ of DNA.

The image bank of individual DAPI-banded $H$. elongata chromosomes consists of 12 chromosome rows: each row represents one of the 12 chromosomes of the set (Fig. 4). Each chromosome row shows the basic structural variations typical for the similar sets. Chromosomes are arranged in row according to decreasing length and, consequently, band visibility (i.e. they have morphological differences). Each row shows all two types of chromosome morphology: chromosomes with conjugated or dissociated SCs. Sister chromatid heteromorphism is related to secondary constrictions of chromosomes with dissociated SCs. Nomenclature used for the description of the individual bands is traditional for animal cytogenetics [31]. Chromatid heteromorphism as

Table 1 Frequencies of chromosomes with dissociated sister chromatids in $H$. elongata chromosome spreads $(N=100)$

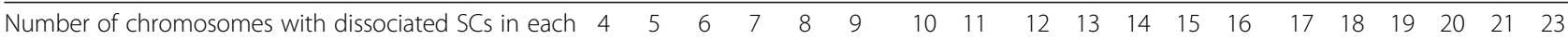
spread

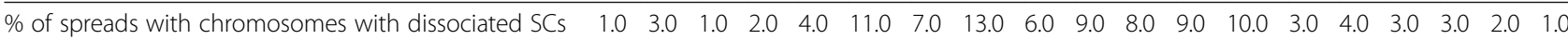

The top row of the table indicates the number of chromosomes with dissociated sister chromatids (SCs) detected in each spread. The bottom row of the table indicates the percent of corresponding cells among 100 spreads analysed 
Table 2 Relative length (means \pm SD) and centromeric index of H. elongata chromosomes

\begin{tabular}{lccl}
\hline Chromosome № & Relative length, \% & Centromeric index, \% & Classification \\
\hline 1 & $14.6 \pm 1.7$ & $37.2 \pm 2.8$ & $\mathrm{~m}$-sm \\
2 & $12.6 \pm 2.1$ & $14.9 \pm 2.3$ & $\mathrm{st}$ \\
3 & $10.8 \pm 2.0$ & $42.2 \pm 3.8$ & $\mathrm{~m}$ \\
4 & $9.4 \pm 1.4$ & $20.2 \pm 3.1$ & $\mathrm{st}$ \\
5 & $8.4 \pm 1.5$ & $21.4 \pm 2.9$ & $\mathrm{st}$ \\
6 & $8.3 \pm 1.6$ & $15.8 \pm 2.6$ & $\mathrm{st}$ \\
7 & $8.2 \pm 1.4$ & $14.8 \pm 2.8$ & st \\
8 & $7.0 \pm 1.1$ & $24.2 \pm 3.4$ & sm-st \\
9 & $6.5 \pm 1.0$ & $24.5 \pm 2.9$ & sm-st \\
10 & $5.6 \pm 1.0$ & $27.1 \pm 3.6$ & sm-st \\
11 & $5.2 \pm 0.9$ & $20.2 \pm 2.8$ & st \\
12 & $4.1 \pm 1.9$ & $20.7 \pm 2.3$ & st \\
\hline
\end{tabular}

$\mathrm{m}$ metacentric, sm submetacentric, st subtelocentric (= acrocentric)

a consequence of chromomere difference is displayed on the ideograms as circles (Fig. 3, legend). The banding pattern of chromosomes with conjugated SCs corresponds to those of one or another dissociated chromatids.

Sister chromatid variability was observed in the majority of analysed chromosome sets. Interchromosomal variability of premature sister chromatid segregation, leading to the appearance of chromosomes with dissociated SCs, can be characterised by data from 100 randomly selected spreads (Table 3).

The chromosome pairs are distinguished by different types of sister chromatid segregation patterns: e.g. pairs 4, 5, and 8-11 are represented mostly in form with dissociated SCs, while some pairs are represented mostly by forms with conjugated SCs - pairs 3,7 , and 12. It appears that chromosomes prefer to segregate in the approximate order: $10>9>8$, and so on.

Differential chromosome DAPI- and $\mathrm{CMA}_{3}$-staining revealed the chromatin areas that varied in AT- and GCcontent. Both dyes stained the chromosomes all along but with fluctuating intensities in different areas. Staining differences were observed between homologues of several chromosomes (Fig. 5, Arrows). A number of terminal bands, dark with AT-specific fluorochrome DAPI, were stained quite pronouncedly by GC-specific fluorochrome $\mathrm{CMA}_{3}$, namely chromosomes 2, 4, 9 and 10 . On the contrary, terminal and centromeric regions of chromosome 5 stained more intensive with DAPI than with $\mathrm{CMA}_{3}$ (Fig. 5).

There was variability in staining between homologs and sister chromatids. A clear example is seen on chromosome 4 (Fig. 5d). This kind of chromosome variability could be associated with the recombination that takes place during the sexual process between adult worms inside definitive host birds.

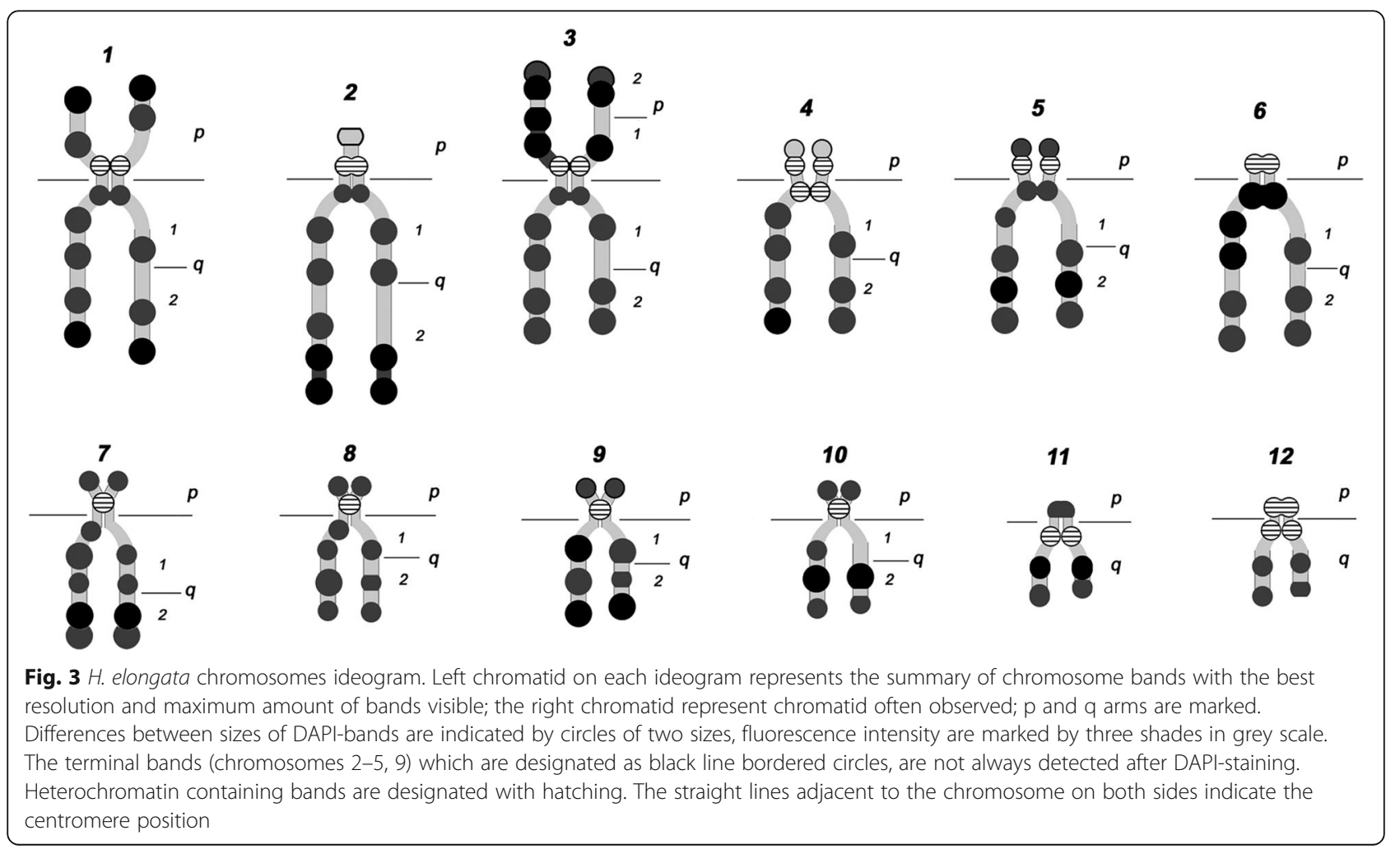




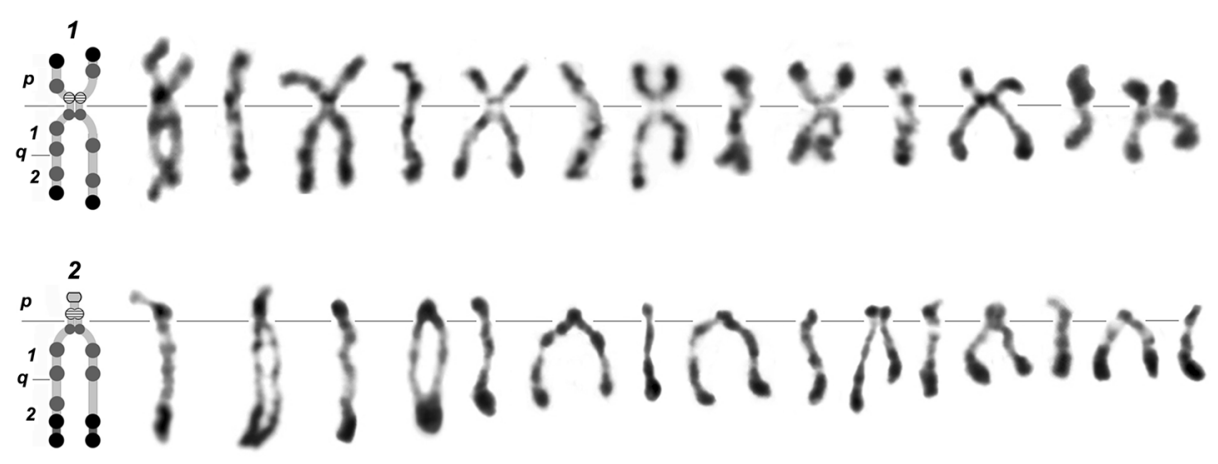

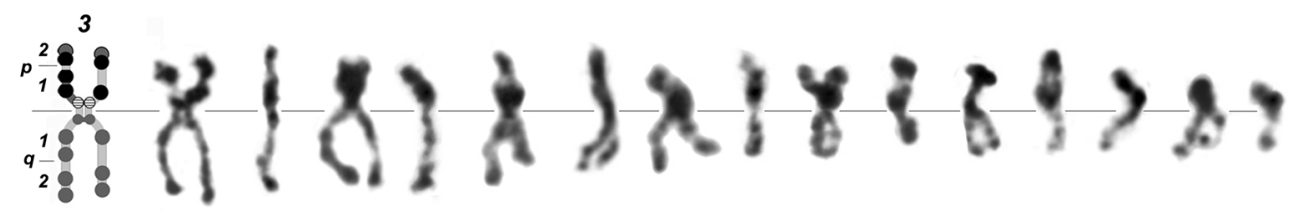

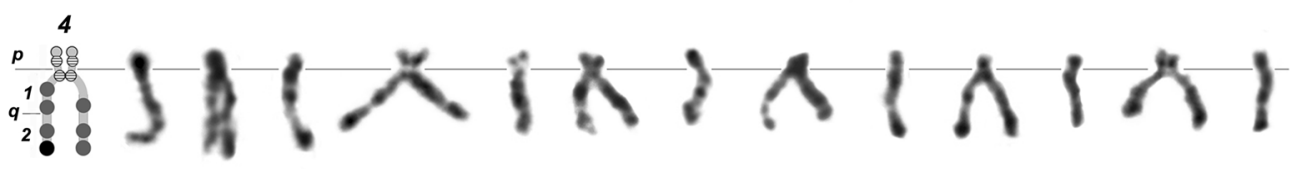

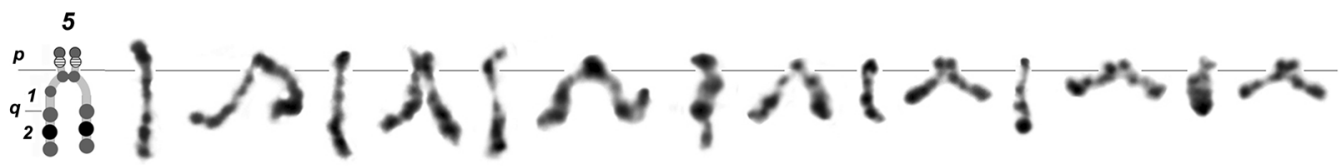

औด

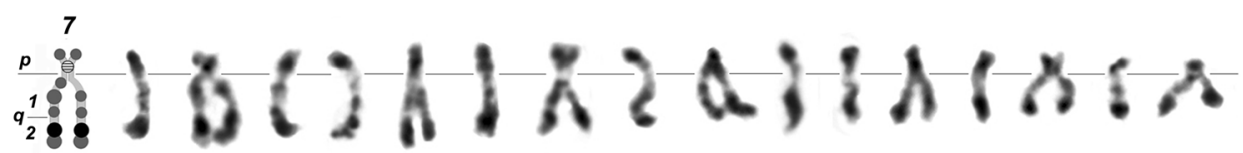

औด

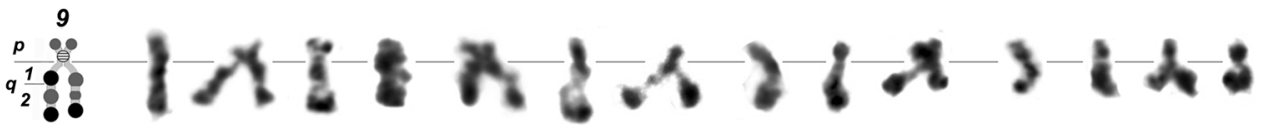

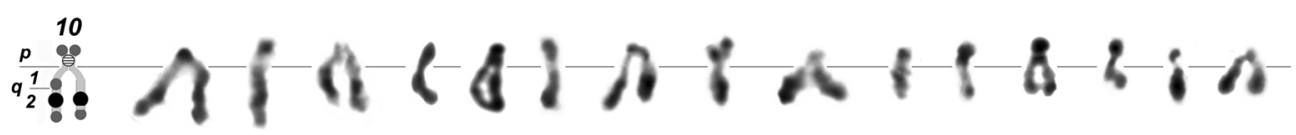

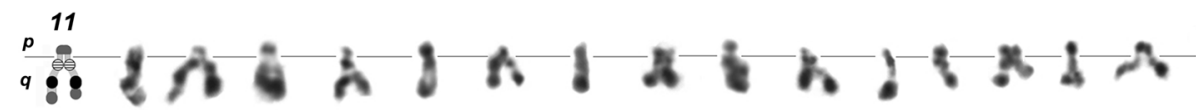

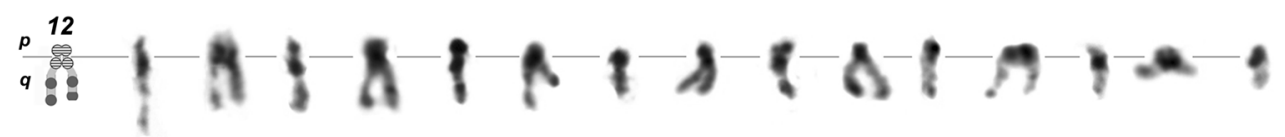


(See figure on previous page.)

Fig. 4 Representative rows of individual DAPI-banded H. elongata chromosomes. Each row begins with the ideogram of chromosome; $p$ and $q$ arms marked; Differences between sizes of DAPI-bands are indicated by circles of two sizes, fluorescence intensity are marked by three shades in grey scale. The following row shows the main chromosome structural variations. Chromosomes are arranged according to decrease of their length and bands' resolution. The straight lines adjacent to the chromosome on both sides indicate the centromere position

FISH of $18 \mathrm{~S}$ rDNA probe revealed that the vast majority (95.0\%) of interphase nuclei contained one signal (Fig. 6 a, $1)$. One signal corresponds to the number of nucleoli per cell in vivo (Fig. 1). Sometimes one or two small nucleoli were also observed in addition to one large nucleolus (Fig. 6 a, 1). A maximum five signals were detected for $18 \mathrm{~S}$ rDNA in interphase nuclei. That corresponded to NORs number, detected by Ag-staining (see Additional file 2: Supplementary methods and Additional file 3: Figure S2). The same was true for the chromosome spreads - most of them contained signal on two chromosomes. Three signals were detected in several cases. The rDNA clusters were located on chromosomes 3, 6 and 10. Physical mapping of $18 \mathrm{~S}$ rDNA clusters on high-resolution $H$. elongata chromosomes (Fig. 6b) uncovered that chromosomes 3 and 10 could contain up to two loci simultaneously on the same arm or on the $\mathrm{p}$ and $\mathrm{q}$ arm of chromosomes. At the same time only one rDNA signal was detected in chromosome 6. Chromosome mapping of $18 \mathrm{~S}$ rDNA in $H$. elongata (Fig. 6) revealed rDNA clusters in chromosome pairs 3, 6 and 10. Two labelled chromosome pairs were detected in $82.0 \%$ of cells observed and three were singly labelled in $18.0 \%$. Only five combinations of two labeled chromosomes (of the six possible) per cell were seen, and a combination of

Table 3 Distribution of different types of homologous sister chromatid segregation in $\mathrm{H}$. elongata chromosomes (100 spreads analysed)

\begin{tabular}{lccc}
\hline Chromosome № & \multicolumn{3}{c}{ Homologous chromosomes combinations } \\
\cline { 2 - 4 } & Dissociated SCs & $\begin{array}{c}\text { Dissociated and } \\
\text { conjugated SCs }\end{array}$ & Conjugated SCs \\
\hline 1 & 15.0 & 45.0 & 40.0 \\
2 & 17.0 & 47.0 & 36.0 \\
3 & 13.0 & 30.0 & 57.0 \\
4 & 59.0 & 26.0 & 15.0 \\
5 & 53.0 & 30.0 & 17.0 \\
6 & 45.0 & 32.0 & 33.0 \\
7 & 16.0 & 35.0 & 49.0 \\
8 & 56.0 & 33.0 & 11.0 \\
9 & 66.0 & 21.0 & 12.0 \\
10 & 74.0 & 20.0 & 6.0 \\
11 & 58.0 & 23.0 & 19.0 \\
12 & 10.0 & 17.0 & 73.0 \\
\hline
\end{tabular}

Columns represent \% of spreads with amount of homologs dissociated or conjugated for correspondent chromosomes chromosomes 3 and 6 was not observed. Approximately $78.9 \%$ of evaluated spreads contained signals on chromosome $10-42.1 \%$ with signal on pair 10 only, $26.3 \%$ in combination with chromosome 3 and $10.5 \%$ in combination with chromosome 6 . Signals on chromosome 6 were found in $28.9 \%$ of spreads (18.4\% with signal only on chromosome 6 and $10.5 \%$ in combination with chromosome 10), and on chromosome 3 in $28.9 \%$ of spreads ( $2.6 \%$ of only chromosome 3 signal and $26.3 \%$ in combination with chromosome 10). The size of signals at different chromosome pairs was generally equal. Ag-staining revealed 5 signals at chromosomes 3, 6 and 10 (Additional file 4: Figure S3). So at this stage of studies we suppose that chromosome 10 possesses the main rDNA cluster with the minor ones existing on chromosomes 3 and 6 .

\section{Discussion}

The goal of the work was the description of the H. elongata chromosome spreads, good enough for further cytogenetic and molecular researches.

In case of using conventional methods, metaphase cell accumulation observed only after prolonged 4-6 h of colchicine treatment of redia in culture medium and only clumpy metaphases unsuitable for future cytogenetic investigations obtained. It was impossible to determine more than one half of the metaphase chromosome set, while separate chromosomes were too condensed for bands identification. Up to $0.5 \%$ per preparations of prometaphase cells suitable for band detection were obtained by suspending rediae after $4 \mathrm{~h}$ and $6 \mathrm{~h}$ of colchicine treatment. Thus, it was necessary to find the appropriate method for obtaining a larger amount of a better prometaphase or metaphase spreads. So in vivo observations helped to detect multiple dividing cells in several rediae tissues and cercarial embryos. Highpressure squash preparation used to improve chromosome spreads resolution. This delicate approach allows to get unbroken even fragile structures of polytene chromosomes. The results reproduced in multiple experiments at $H$. elongata spreads without significant chromosome damages.

There are morphologic polymorphisms in the number of spreads revealed varying levels of sister chromatid segregation (Tables 1 and 3 ) and discordance among homologous chromosomes. Partial sister chromatid segregation in $H$. elongata cells is always accompanied by a 

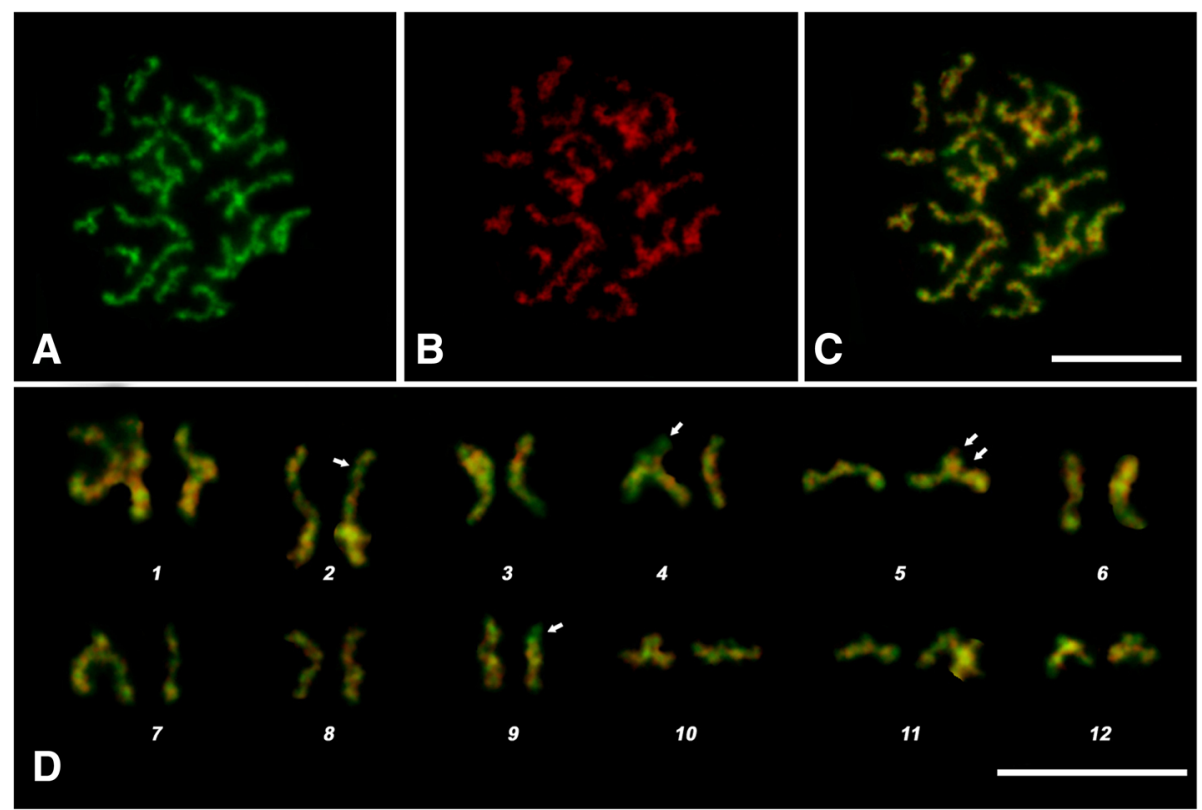

Fig. 5 a H. elongata chromosomes stained by $\mathrm{CMA}_{3}$. $\mathbf{b}$ DAPI-stained chromosomes (c) merged image (d) karyotype derived from the cell shown in Fig. 6c. Arrows indicate polymorphic sites detected by double fluorochrome staining. Scale bar - $10 \mu \mathrm{m}$

pronounced asymmetry in the level of chromatin condensation and (or) the band pattern. The phenomenon of homologue discordance is well established for human chromosomes. It was shown that the discordance minimum values $(6.7$ - $14.2 \%)$ were observed at metaphase after GTG chromosome banding (G-banding with trypsin-Giemsa), whereas prometaphase chromosomes varied in size and had greater homolog discordance - up to $29.8 \%$ after GTG and $64.2 \%$ RBG (R-banding using bromodeoxyuridine and Giemsa) banding [32].
Homologue discordance has been widely discussed in the literature in terms of embryogenesis [33] and tissue specific stem cell differentiation [34], as well as asymmetry in cell division and tissue differentiation during embryogenesis [35-37]. Thus, the image bank for $H$. elongata karyotype component was made in order to detect all probable variabilities in chromosome morphology.

Representative rows for $H$. elongata individual chromosomes (Fig. 4) served for identification of individual

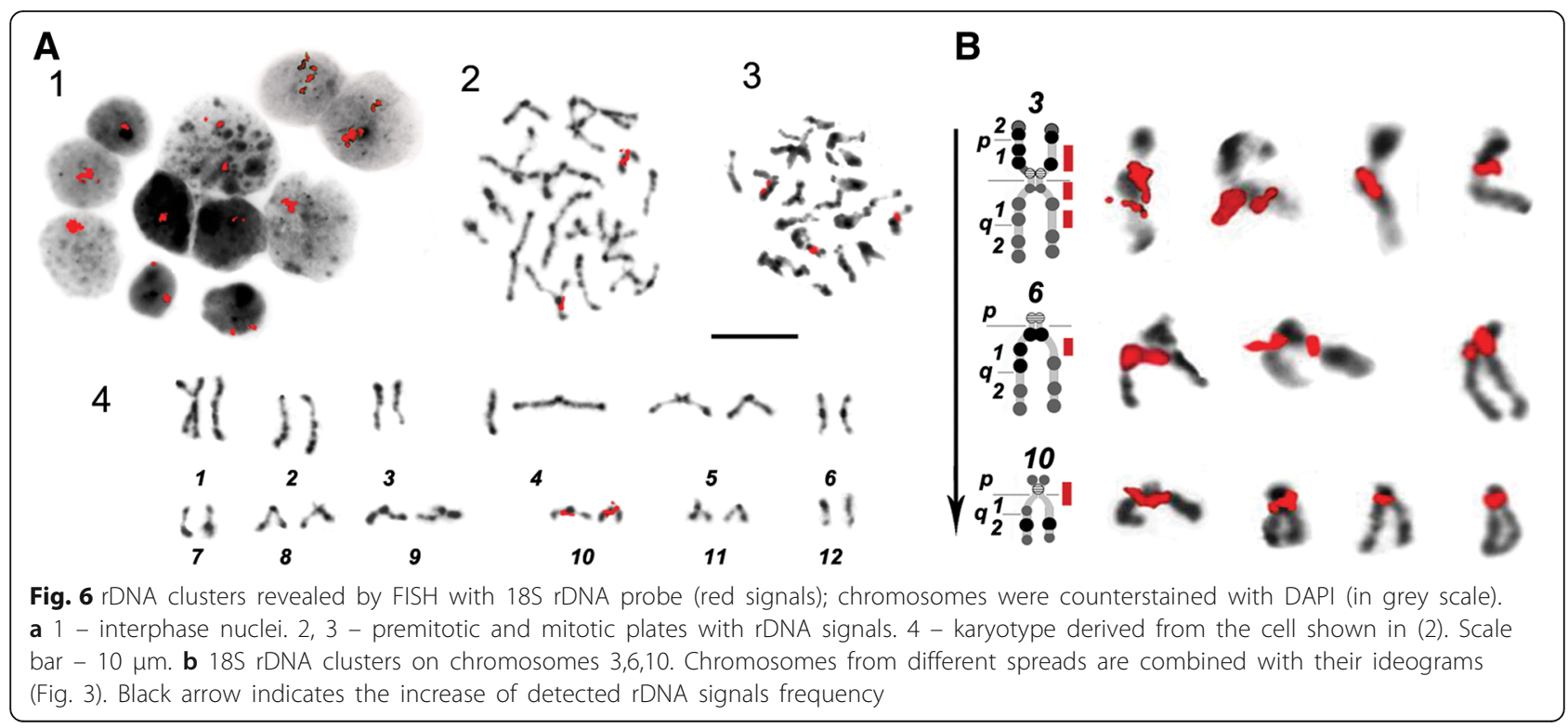


chromosomes of prometaphase and metaphase sets. Individual chromosome variation was estimated by the following criteria: cohesion and incomplete sister chromatid segregation, banding pattern, centromeric heterochromatin and the possibility of distinguishing terminal bands by DAPI-staining. A more detailed description of homologs discordance and sister chromatids' segregation variability requires additional study. Right now, we point out that one spread can contain homologs with resolutions corresponding to the extreme right and left positions in the chromosome identification rows (Fig. 5). The chromosome shapes are the superposition of two events: (1) the degree of condensation, which reflects mitosis advance; (2) the extent of sister chromatids' segregation.

Centromeric heterochromatin blocks' size variations, different from other morphological changes, may potentially reflect population variability. The source of such polymorphism could be found with the determination of species major tandem repeat, the main constituent of heterochromatic regions. It is possible that the first steps of $H$. elongata genome sequencing will bring up a major tandem repeat of this species. Such a repeat will serve as a reliable probe to assess heterochromatin block variability. Right now, it may only be supposed that possible heterozygosity of large heterochromatin blocks visible in many chromosome sets could be associated with cross fertilisation in adult flukes. The intercellular variation observed in heterochromatin does not exclude the possibility of polymorphism in parthenogenetic clonal populations.

Noticeable banding pattern along $H$. elongata chromosome arms visible after differential DAPI- and $\mathrm{CMA}_{3}$-staining. It is widely accepted that clear G- and Rblocks, typical for higher vertebrate chromosomes, are heterochromatic and euchromatic regions, respectively [38]. In the current work such banding is obtained for the flatworm karyotype for the first time. Echinostoma caproni is the nearest $H$. elongata relative, whose genome size is known - $0.85 \mathrm{pg}$ [39]. Unfortunately, E. caproni karyotype is performed by Giemsa staining and $C$ bands (centromeric) were described [10] and no detailed ideograms were made.

From 40.0 to $95.0 \%$ of ribosomal DNA is in the inactive state in animal cells [40]. FISH identification of genes in heterochromatin requires increased chromosome deproteinisation to improve hybridization conditions. Chromosome mapping of inactive rDNA clusters is a common problem of animals cytogenetics with no universal solution so far. Even short-term treatment with pepsin and proteinase $\mathrm{K}$ led to the complete disappearance of the chromomere patterns on $H$. elongata chromosomes. We used the 18S rDNA FISH protocol without any protease treatment. All signals detected with
rDNA FISH were also revealed by Ag-staining. Thus, there are at least 3 nucleoli organizing chromosomes in H. elongata karyotype.

Before very recent phylogenetic update [2] H. elongata belonged to Echinostomatidae Looss, 1899 family and following discussion focuses at "old" family state. Karyological data for the Echinostomatidae Looss, 1899 family was available for a rather small number of species whose intermediate hosts are freshwater molluscs and final hosts are birds, pets and humans. The diploid number of chromosomes in the Echinostomatidae family varies from 14 to 22 according to the literature available (Table 4). There is debate about the existence of an evolutionary tendency in the Digenea to maintain the diploid number equal to 20 , which seems to be ancestral [11]. No karyological data on any of Himasthla species have been described yet. Based on chromosome number $(2 \mathrm{n}=24) H$. elongata slightly deviates from the previously studied echinostomatids $(2 \mathrm{n}=14-22)$. H. elongata karyotype consists of two pairs of large chromosomes and 10 pairs of smaller-sized chromosomes. In contrast with a previous reports collected and analysed by

Table 4 Chromosome number described for Echinostomatidae Looss, 1899 family representatives before recent phylogenetic update [2]

\begin{tabular}{lll}
\hline Species & $\begin{array}{l}\text { Chromosome } \\
\text { number (2n) }\end{array}$ & Reference \\
\hline Echinochasmus baleocephalus & 14 & Barsiene, Kiseliene, 1990 [42] \\
Echinochasmus sp & 20 & Staneviciute et al. 2015 [43] \\
Echinoparyphium aconiatum & 20 & Mutafova, Kanev, 1984 [44] \\
Echinoparyphium recurvatum & 20 & Mutafova et al. 1987 [45] \\
Echinoparyphium pseudorecurvatum & 20 & Barsiene et al. 1990 [46] \\
Echinostoma barbosai & 22 & Mutafova, Kanev, 1983 [47] \\
Echinostoma caproni & 22 & Richard, Voltz, 1987 [10] \\
Echinostoma echinatum & 22 & Mutafova, Kanev, \\
Echinostoma revolutum & 22 & 1983; 1986 [47, 48] \\
Echinostoma cinetorchis & 22 & Mutafova, Kanev, \\
Echinostoma hortense & 20 & 1983; 1986 [47, 48] \\
Episthmium bursicola & 20 & Terasaki et al. 1982 [49] \\
Hypoderaeum conoideum & 20 & Barsiene, Kiseliene, 1990 [42] \\
Isthmiophora melis & 20 & Mutafova et al. 1986 [50] \\
Moliniela anceps & 20 & Mutafova, et al. 1991 [12] \\
Neoacantoparyphium echinoides & 20 & Barsiene et al. 1990 [51] \\
Paryphostomum radiatum & 16 & Mutafova, 1994 [13] \\
Pegosomum asperum & 20 & Mutafova, 1994 [13] \\
Pegosomum saginatum & 20 & Aleksandrova, Podgornova, \\
Sphaeridiotrema globulus & 22 & 1978 [52] \\
\hline & & Mleksandrova, Podgornova, \\
& & Mutafova et al. 2001 [53] \\
\hline
\end{tabular}


Garcia-Souto and J. Pasantes [41] where single loci of major rDNA clusters are described in several digeneans, we revealed multiple signals of rDNA at 3 chromosome pairs in $H$. elongata karyotype. The lack of karyological data on the other Himasthla species doesn't allow any speculation about chromosome number characteristic for this genus. More precise evaluation of karyotype components could be performed by geographic population of $H$. elongata expansion and involvement of other Himasthla species.

\section{Conclusions}

In the current work karyotype of the first representative of Himastla genus determined. It is shown that $H$. elongata karyotype consists of two pairs of large chromosomes and 10 pairs of smaller-sized chromosomes. Differential DAPIand $\mathrm{CMA}_{3}$-staining revealed the $\mathrm{AT}$ - and GC-rich chromosome bands. The identification of nucleoli organizing chromosomes was performed with $18 \mathrm{~S}$ rDNA FISH and Ag-staining. The main rDNA cluster was observed on chromosome 10 with minor examples on chromosomes 3 and 6 .

\section{Additional files}

Additional file 1: Figure S1. Flow cytometry profile of $2 \mathrm{C}$ peaks for the species indicated. $X$ axis - the relative pripidium iodide (PI) fluorescence intensity at FL3 channel; Y-axis, the number of events. (TIF $88 \mathrm{~kb}$ )

Additional file 2: Supplementary methods. (DOC $16 \mathrm{~kb}$ )

Additional file 3: Figure S2. Ag-staining of $\mathrm{H}$. elongata nuclei. Nuclei with more than two Ag-NORs detected are shown in B, C, E, F, G. Scale bar $-10 \mu \mathrm{m}$. (TIF $4102 \mathrm{~kb}$ )

Additional file 4: Figure S3. Correspondence of Ag-NOR-staining and rDNA FISH signals at aneuploid metaphase spread of $\mathrm{H}$. elongata. A metaphase spread. B - karyotype of the metaphase spread shown in A. Asterisks mark the correspondent chromosomes with rDNA FISH signals at (main text, Fig. 6). Scale bar - $10 \mu \mathrm{m}$. (TIF $481 \mathrm{~kb}$ )

\section{Competing interests}

The authors declare that they have no competing interests.

\section{Authors' contributions}

Research concept and design: AS, DS, OP. Material collection AS. Performed the experiments: AS, DS, VS. Image and data analysis: DS, AS. Wrote the paper: DS, AS, OP, VS. All authors read and approved the final version of the manuscript.

\section{Acknowledgements}

This work was supported by the Russian Foundation for Basic Research (grants № 05-04-49156-a, 11-04-01700, 15-04-01857), the Russian Science Foundation (grant no.15-15-20026), and the granting program for "Molecular and Cell Biology" of the Presidium of Russian Academy of Sciences (№ 01.2.00 955639). Editing and publishing costs have been paid for by a grant from the Russian Science Foundation (grant №15-15-20026). We deeply appreciate our colleagues, especially Prof. Kirill Galaktionov and Dr. Ivan Levakin, of the Zoological Institute RAS White Sea Biological Station "Kartesh" for provided support and constant attention. We also thank Dr. Nikolai Aksenov of the Flow cytometry and sorting group at Institute of Cytology RAS for kind advises and help with genome size evaluation. The work was partially carried out at the Development of Molecular and Cellular Technologies Resource Center at St. Petersburg University (project № 1.50.1042.2014).

\section{Author details}

${ }^{1}$ Institute of Cytology RAS, St. Petersburg 194064, Russia. ${ }^{2}$ Saint Petersburg State University, St. Petersburg 199034, Russia. ${ }^{3}$ Far Eastern Federal University, Vladivostok 690922, Russia.

Received: 11 February 2016 Accepted: 12 April 2016

Published online: 29 April 2016

\section{References}

1. Schmidt GD, Roberts LS. Foundations of parasitology, 6th ed. Boston: McGraw-Hill Comp; 2000. p. 209-33.

2. Tkach W, Kudlai O, Kostadinova A. Molecular phylogeny and systematics of the Echinostomatoidea Looss, 1899 (Platyhelminthes: Digenea). Int J Parasitol. 2016;46(3):171-85.

3. Stunkard HW. Further studies on the trematode genus Himasthla with descriptions of H. mcintoshi n. sp., H. piscicola n. sp., and stages in the lifehistory of H. compacta n. sp. Biol Bull. 119(3):529. doi: 10.2307/1539266

4. Nikolaev KE, Sukhotin AA, Galaktionov KV. Infection patterns in White Sea blue mussels Mytilus edulis $L$. of different age and size with metacercariae of Himasthla elongata(Mehlis, 1831) (Echinostomatidae) and Cercaria parvicaudata Stunkard \& Shaw, 1931 (Renicolidae). Dis Aquat Organ. 2006;71:51-8.

5. Levakin IA, Losev EA, Nikolaev KE, Galaktionov KV. In vitro encystment of Himasthla elongata cercariae (Digenea, Echinostomatidae) in the hemolymph of blue mussels Mytilus edulis as a tool for assessing cercarial infectivity and molluscan susceptibility. J Helminthol. 2012;87:180-8.

6. Solovyeva Al, Galaktionov NK, Podgornaia OI. LINE class retroposon is the component of the DNA polymorphic fragments pattern of trematode Himasthla elongata parthenitae. Cell Tissue Biol. 2013;7(6):563-72.

7. Gorbushin AM, Borisova EA. Himasthla elongata: implantation of rediae to the specific iteroparous long-living host, Littorina littorea, results in the immune rejection. Fish Shellfish Immunol. 2014;39(2):432-8.

8. Werding B. Morphologie, Entwicklung und Okologie digener TrematodenLarven der Strandschnecke Littorina littorea. Marine Biol. 1969;3:306-33.

9. Kapuscinski J. DAPI: a DNA-specific fluorescent probe. Biotech Histochem. 1995;70(5):220-33.

10. Richard J, Voltz A. Preliminary data on the chromosomes of Echinostoma caproni Richard, 1964 (Trematoda: Echinostomatidae). Syst Parasitol. 1987:9:169-72.

11. Birstein VJ, Mikhailova NA. On the karyology of trematodes of the genus Microphallus and their intermediate gastropod host, Littorina saxatilis I.Chromosome analysis of three Microphallus species. Genetica. 1990;80:159-65.

12. Mutafova T, Kanev I, Eizenhut U. Karyological studies of Isthmiophora melis(Schrank, 1788) from its type locality. J Helminthol. 1991;65:255-8.

13. Mutafova T. Karyological studies on some species of the families Echinostomatidae and Plagiorchiidae and aspects of chromosome evolution in trematodes. Syst Parasitol. 1994;28:229-38.

14. Deng W, Tsao SW, Lucas JN, Leung CS, Cheung AL. A new method for improving metaphase chromosome spreading. Cytometry Part A. 2003;51(1): 46-51.

15. Hirai H, Hirai Y. FISH mapping for Helminth genomes. Methods Mol Biol. 2004;270:379-94.

16. Novikov DV, Kireev I, Belmont AS. High-pressure treatment of polytene chromosomes improves structural resolution. Nat Methods. 2007;4(6): 483-5.

17. George P, Sharakhova MV, Sharakhov IV. High-resolution cytogenetic map for the African malaria vector anopheles gambiae. Insect Mol Biol. 2010;19(5):675-82.

18. Bayha KM, Dawson MN, Collins AG, Barbeitos MS, Haddock SH. Evolutionary relationships among scyphozoan jellyfish families based on complete taxon sampling and phylogenetic analyses of $18 \mathrm{~S}$ and $28 \mathrm{~S}$ ribosomal DNA. Integr Comp Biol. 2010;50(3):436-55.

19. Altschul SF, Gish W, Miller W, Myers EW, Lipman DJ. Basic local alignment search tool. J Mol Biol. 1990;5:403-10.

20. Winnepenninckx B, Backeljau T, De Wachter R. Extraction of high molecular weight DNA from molluscs. Trends Genet. 1993;9:407.

21. Khodyuchenko T, Gaginskaya E, Krasikova A. Non-canonical Cajal bodies form in the nucleus of late stage avian oocytes lacking functional nucleolus. Histochem Cell Biol. 2012;138(1):57-73. 
22. Scweizer D. Reverse fluorescent chromosome banding with chromomycin and DAPI. Chromosoma. 1976;58:307-24.

23. UTHSCSA ImageTool Version 3.0 Final. Available from: http://www.uthscsa. edu/academics/dental/departments/comprehensive-dentistry/imagetool/ downloads. Accessed 5 Nov 2014.

24. Levan A, Fredga K, Sandberg AA. Nomenclature for centromeric position on chromosomes. Hereditas. 1964;52(2):201-20.

25. Demin S, Pleskach N, Svetlova M, Solovjeva L. High-resolution mapping of interstitial telomeric repeats in Syrian hamster metaphase chromosomes. Cytogenet Genome Res. 2011;132(3):151-5.

26. Whitfield PJ. Trematoda: form, function, and classification of digeneans. In: Foundations of Parasitology. 6th ed. Boston: McGraw-Hill Comp; 2000. p. 209-33.

27. Jhanwar SC, Burns JP, Alonso ML, Hew W, Chaganti RS. Mid-pachytene chromomere maps of human autosomes. Cytogenet Cell Genet. 1982:33(3):240-8.

28. Jhanwar SC, Chaganti RS. Pachytene chromomere maps of Chinese hamster autosomes. Cytogenet Cell Genet. 1981;31(2):70-6.

29. Galaktionov NK, Solovyeva Al, Fedorov AV, Podgornaya Ol. Trematode H. elongata mariner element (Hemar): structure and applications. J Exp Biol B. 2014;322(3):142-55.

30. Dolezel J, Bartos J, Voglmayr H, Greilhuber J. Nuclear DNA content and genome size of trout and human. Cytometry A. 2003;51(2):127-8.

31. Nesbitt MN, Francke U. A system of nomenclature for band patterns of mouse chromosomes. Chromosoma. 1973;41:145-58.

32. Schwartz S, Palmer CG. High-resolution chromosome analysis: I. Applications and limitations. Am J Med Genet. 1984;19(2):291-9.

33. Patkin EL. Epigenetic mechanisms for primary differentiation in mammalian embryos. Int Rev Cytol. 2002;216:81-129.

34. Tran V, Feng $L$, Chen X. Asymmetric distribution of histones during Drosophila male germline stem cell asymmetric divisions. Chromosome Res. 2013;21:255-69.

35. Bell CD. Is mitotic chromatid segregation random? Histol Histopathol. 2005;20:1313-20.

36. Tajbakhsh S, Rocheteau P, Le Roux I. Asymmetric cell divisions and asymmetric cell fates. Ann Rev Cell Dev Biol. 2009;25:671-99.

37. Lansdorp PM, Falconer E, Tao J, Brind'Amour J, Naumann U. Epigenetic differences between sister chromatids? Ann NY Acad Sci. 2012;1266:1-6.

38. Rodionov AV. Evolution of differential chromosome banding. Genetika. 1999;35(2):277-90

39. WormBase ParaSite release 3. EMBL-EBI \& WTSI, 2015 http://parasite wormbase.org/Echinostoma_caproni_prjeb1207/Info/Annotation/. Accessed 12 Dec 2015.

40. Grummt I. Life on a planet of its own: regulation of RNA polymerase I transcription in the nucleolus. Genes Dev. 2003;17(14):1691-702.

41. Garcia-Souto D, Pasantes JJ. Molecular cytogenetics in Digenean parasites: linked and unlinked major and $5 \mathrm{~S}$ rDNAs, B chromosomes and karyotype diversification. Cytogenet Genome Res. 2015;147(2-3):195-207.

42. Barsiene J, Kiseliene $V$. Karyological studies of trematodes within the families Psilostomidae and Echinochasmidae. Helminthologia. 1990;27:99-108.

43. Stanevičiūtè $G$, Stunžènas V, Petkevičiūtè R. Phylogenetic relationships of some species of the family EchinostomatidaeOdner, 1910 (Trematoda), inferred from nuclear rDNA sequences and karyological analysis. Comp Cytogenet. 2015;9(2):257-70.

44. Mutafova T, Kanev I. Studies on the karyotype of Echinoparyphium aconiatum Diez, 1909 (Trematoda:Echinostomatidae). Helminthology (Bulg). 1984;17:37-40.

45. Mutafova T, Kanev I, Vassilev I. Comparative karyological investigations of Echinoparyphium aconiatum Dietz, 1909, and Echinoparyphium recuriatum (Linstow, 1873) Dietz, 1909 (Trematoda: Echinostomatidae). Helminthology (Bulg). 1987;24:32-6.

46. Barshene W, Pyatkyavichyute RB, Stanyavichyute Gl, Orlovskaya OM. Karyological studies of trematodes from the families Notocotylidae, Echinostomatidae and Strigeidae in north-western Chukotka. Parazitologiya. 1990;24(1):3-11.

47. Mutafova T, Kanev I. Studies on the karyotype of the echinostome Echinostoma barbosai Lie et Basch, 1966 (Trematoda: Echinostomatidae) from Bulgaria. Helminthology (Bulg). 1983;16:42-6.

48. Mutafova T, Kanev I. Studies on the karyotype of Echinostoma revolutum (Fre1ich, 1802) and Echinostoma echinatum (Zeder, 1803) (Trematoda: Echinostomatidae). Helminthology (Bulg). 1986;22:37-41.

49. Terasaki K, Moriyama N, Tanis S, Ishida K. Comparative studies on the karyotypes of Echinostoma cinetorchis and E. hortense (Echinostomatidae: Trematoda). Jpn J Parasitol. 1982;31:569-74.
50. Mutafova T, Kanev I, Angelova R. Studies on the karyotype of Hypoderaeum concideum (Blanch, 1782) Dietz, 1909 (Trematoda: Echinostomatidae). Helminthology. 1986;22:33-6

51. Barsiene J, Kiseliene V. Grabda - Kazubska B. Karyotypes of Isthmiophora melis (Schrank, 1788) and Moliniella anceps (Molin, 1858) (Trematoda: Echinostomatidae). Acta Parasitol Polonica. 1990;35:265-9.

52. Aleksandrova OV, Podgornova GP. Taxonomic analysis of Pegosomum asperum and $P$. saginatum (Trematoda: Echinostomatidae). Parazitologiia. 1978;12(5):413-7.

53. Mutafova T, Kanev I, Panaiotova M. A cytological study of Sphaeridiotrema globulus (Rudolphi, 1819) Odhner, 1913. Exp Pathol Parasitol. 2001:4(5):24-5.

\section{Submit your next manuscript to BioMed Central and we will help you at every step:}

- We accept pre-submission inquiries

- Our selector tool helps you to find the most relevant journal

- We provide round the clock customer support

- Convenient online submission

- Thorough peer review

- Inclusion in PubMed and all major indexing services

- Maximum visibility for your research

Submit your manuscript at www.biomedcentral.com/submit
) Biomed Central 